\title{
Polyhexamethylene Biguanide in Vaginal Solution Is Effective in the Treatment of Vulvovaginal Candidiasis: A Pilot Study
}

\author{
Alberto Biamonti*, Angela Saracino \\ O. U. (Operative Unit) Obstetrics \& Gynecology, Cristo Re Hospital, Via delle Calasanziane, Rome, Italy \\ Email: *a.biamonti@tin.it
}

How to cite this paper: Biamonti, A. and Saracino, A. (2017) Polyhexamethylene Biguanide in Vaginal Solution Is Effective in the Treatment of Vulvovaginal Candidiasis: A Pilot Study. Open Journal of Obstetrics and Gynecology, 7, 7-15.

http://dx.doi.org/10.4236/ojog.2017.71002

Received: June 28, 2016

Accepted: December 20, 2016

Published: December 23, 2016

Copyright $\odot 2017$ by authors and Scientific Research Publishing Inc. This work is licensed under the Creative Commons Attribution International License (CC BY 4.0).

http://creativecommons.org/licenses/by/4.0/

\begin{abstract}
Vaginitis is one of the most recurrent conditions that afflict women and require medical care. Vulvovaginal candidiasis (VVC) is frequently related to vaginal carriage of Candida albicans, an opportunistic polymorphic fungus, which colonizes the human skin, the mucosa and the reproductive tract. Actually, standard treatments to counteract vaginitis include several topical and oral treatments. The aim of this study was to evaluate the efficacy of a new biguanide compound, polyhexamethylene biguanide (PHMB) in avaginal solution, in women affected by vaginal candidiasis. For this reason, 40 women showing the symptoms previously ascribed to vaginal candidiasis were recruited and treated with a single PHMB dose of vaginal solution. After a single dose of treatment, $80 \%$ of them had a complete resolution of the fungal infection; furthermore, all of them reported clinical benefits, statistically significant reduction in both clinical signs and symptoms of candidiasis and a score's reduction of $50 \%$.
\end{abstract}

\section{Keywords}

Polyhexamethylene Biguanide, Vulvovaginal Candidiasis,

Candida albicans Infection, Biguanide, Antiseptic

\section{Introduction}

Vaginitis represents one of the most recurrent conditions for which women need medical care and it can be due to a wide variety of causes, often associated with infections or atrophic changes. The most common infections include bacterial vaginosis, vulvovaginal candidiasis and trichomoniasis. Among them, vulvovaginal candidiasis (VVC) is often related to vaginal carriage of Candida spp. [1]. Over the years, VVC has been classified into two different subtypes related to the duration and the frequency of the disease: uncomplicated/acute VVC or recurrent/complicated VVC. The first one is 
characterized by sporadic and infrequent $C$. albicans infections. It is a common condition that affects $75 \%$ of women during their lives. The other form (RVVC) is defined as 4 or more episodes (of VVC) in a year, involving about $5 \%$ of women usually due to non- $C$. albicans species [2]. Almost all the patients with vaginitis report more than one of the following symptoms: itching, burning, pain, vulvar redness and vaginal mucosa often associated to vaginal discharge. Clinical symptoms include vulvar oedema, erythema and scratches. Although Candida albicans is an opportunistic polymorphic fungus, usually found in the normal vaginal microbiota. Its transition from yeast to hyphae is under control of a complex set of environmental sensors and it is responsible for the virulence of this pathogen [3]. Standard regimens for uncomplicated vulvovaginal candidiasis include various topical treatments or a single oral dose of fluconazole $150 \mathrm{mg}$, an agent that may cause some side effects (gastrointestinal issues, headache, dizziness, rashes) [4]. Topical treatments of acute vulvovaginal candidiasis (administration schedule from 1 to 7 days) include drugs like nystatin, imidazoles, ciclopiroxolamine, triazoles and antimycotic creams in several pharmaceutical dosage forms, such as vaginal tablets, suppositories or creams. All the different regimens produced similarly good clinical and mycological results, even though these substances may influence the physiological vaginal flora [5]. Some alternative, such as topical antiseptics, may be used as protective agents against fungal vaginitis, such as chlorhexidine. However, the efficacy of such products has shown some bounds due to the contact time with vaginal mucosa [6]. Polyhexamethylene biguanide (PHMB) is a new antiseptic agent that showed good results in different therapeutic areas, including gynaecology as treatment for bacterial infections [7] [8] [9] [10] [11]. The aim of this pilot study was to test $\mathrm{PHMB}$ as a new approach to treat vulvovaginal candidiasis infections.

\section{Patients and Methods}

Between November 2013 and April 2014, in department of Cristo Re Hospital, 40 women suffering for symptoms previously ascribed to vaginal candidiasis were selected for the inclusion in the study. Before any study-related procedure, all the patients signed a written informed consent, and all clinical investigations were conducted according to the principles of the Declaration of Helsinki. Eligible criteria included women between 18 - 45 years (mean age 33.5), with BMI $<27$ and with clinical diagnosis of VVC. The clinical diagnosis was performed with a mycological culture and confirmed by potassium hydroxide $(\mathrm{KOH})$ microscopy, showing one of the dimorphic forms (hyphae/pseudo-hyphae or budding yeasts). Furthermore, signs and symptoms evaluation was recorded with a score of a 4-point rating scale, where $0=$ absent, $1=$ mild, 2 = moderate and 3 = severe. Patients with microscopic analysis excluded by culture, pregnancy, severe chronic diseases, immuno-suppressive treatments, use of oral hypoglycaemic agents, local or systemic treatment with anti-fungal and antibiotics within two weeks of the study or during the treatment were excluded. Eligible patients were examined before treatment (T0), then after 21 days (T1) at the end of the study. The provided treatment was a single dose of PHMB $0.10 \%$ invaginal solution (Monogin/Biguanelle LOLI Pharma, Rome) self-administered by patients. Patients were trainedonthe appropriate treatments administration. Clinical cure was defined as reso- 
lution of signs and symptoms, plus the absence of positive mycological culture and $\mathrm{KOH}$ wet microscopy.

\section{Statistical Analysis}

A statistical analysis of the data collected during the study was performed. The few patients led us to adopt Fisher's exact test for assessing significance instead of chi-square, for the whole data set regarding score analysis. $P<0.0001$ was estimated extremely significant. Student's $\mathrm{T}$ test was used to assess significance in total score's reduction.

\section{Results}

The socio-demographic characteristics of enrolled patients is shown in Table 1. The average age of these women was $33.5(\mathrm{SD} \pm 4$ ) and average $\mathrm{BMI}$ was $23.1(\mathrm{SD} \pm 3.3)$. All the 40 patients accomplished the cure and completed the planned screening in 21 days. No side effects were reported on the group and all of them adhered to the treatment, because of the easier use of PHMB single-dose self-administration.

All the patients experienced a clinical benefit with PHMB 0.10\% vaginal solution. A statistically significant reduction of all symptoms and clinical signs was registered in the entirety of subjects. In particular, for what concerns symptoms, there was a decrease of $33 \%$ in itching, $25 \%$ in burning and $27 \%$ in inflammation, compared to the starting percentages (Figure 1). In general, the difference $(\Delta)$ between pre-treatment (T0) and at the end of the study (T1) was included between $25 \%$ and $33 \%$ for symptoms and between $10 \%$ and $18 \%$ for signs, as shown in Figure 1. At the end of the study there was a significant total score's reduction of 50\% (Table 2).

Furthermore, regarding the clearance of infection, before treatment (T0) 40 patients were affected by candidiasis and 6of them accused a mixed infection. Instead, at T1, 32 patients (80\%) did not show candidiasis and no one presented mixed infection (Table $3)$.

Percentage difference $(\Delta)$ in clinical signs and symptoms between pre-treatment (T0) and at the end of the study (T1).

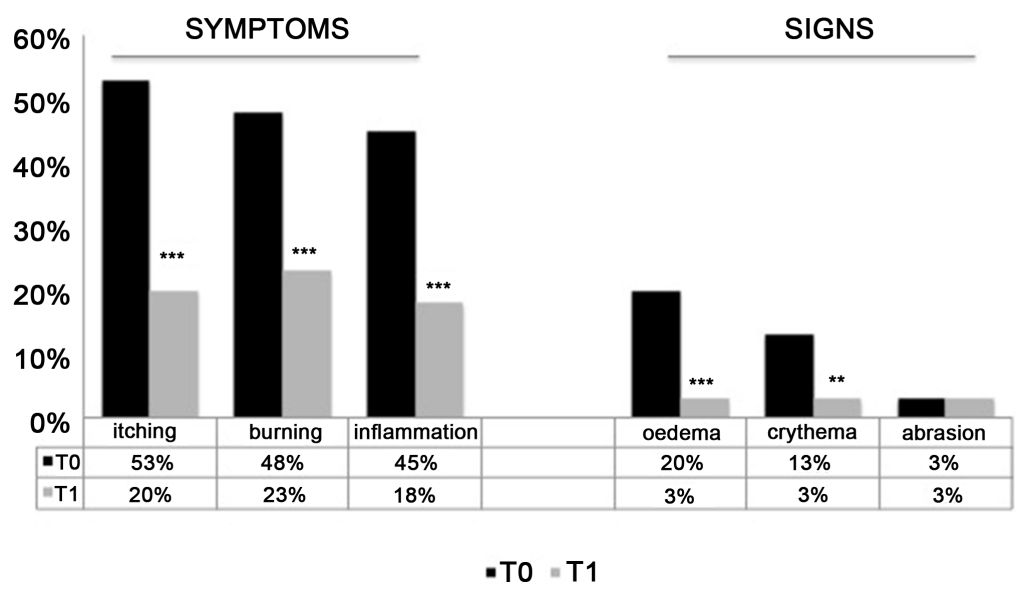

Figure 1. Percentage difference $(\Delta)$ in clinical signs and symptoms between pre-treatment (T0) and at the end of the study (T1). Fisher's exact test. ${ }^{* *} P<0.0001 ;{ }^{* *} P<0.001$. 
Table 1. Baseline socio-demographic characteristics of the enrolled 40 patients.

\begin{tabular}{ccc}
\hline & Age & BMI \\
\hline Baseline characteristics & $33.5 \pm 4$ & $23.1 \pm 3.3$ \\
\hline
\end{tabular}

Table 2. Total score's reduction per patient, between pre-treatment (T0) and at the end of the study (T1). Student's T test.

\begin{tabular}{cccc}
\hline & Mean & s.d. & $P$ value \\
\hline Pre-treatment (T0) & 6.125 & 3 & $P<0.0001$ \\
Ending study (T1) & 3.1 & 3.1 & \\
\hline
\end{tabular}

Table 3. Infection's clearance between pre-treatment (T0) and at the end of the study (T1).

\begin{tabular}{ccc}
\hline & Pre-treatment $(\mathrm{T} 0) \mathrm{n}^{\circ}(\%)$ & Ending study $(\mathrm{T} 1) \mathrm{n}^{\circ}(\%)$ \\
\hline Candidiasis & $40(100 \%)$ & $8(20 \%)$ \\
Mixed infections & $6(15 \%)$ & none \\
\hline
\end{tabular}

\section{Discussion}

Vaginitis is a complex disease requiring a perfect sequence of events to start the infection. The microbiology of vagina is a complex example of microbial colonization hosting different types of microorganisms. Normally, if there is a balance between these organisms and microenvironment, health is guaranteed, in other cases several complex factors contribute to initiate infection [12]. Vaginal candidiasis (VVC) is one of the recurring infections in women. It has been estimated that $50 \%-75 \%$ of women are affected by VVC at some points in their lives [13]. In a previous study of Glover and Larsen [14], the results of subsequent cultures of vaginal flora specimens obtained from women who were followed throughout pregnancy, indicated that Candida species might be present in stable association with the genital epithelium. If the number of colony-forming units of Candida species that are present in the tissue-invasive form significantly increases, then vulvovaginal candidiasis occurs [15]. The first step between colonisation and infection is the adhesion of the Candida to the vaginal epithelium with the help of mannoproteins [16]. Overall, several properties of $C$. albicans play a relevant role in the ongoing disease: morphogenesis, secreted factors and biofilm formation. The transition from yeast to hyphae is under the control of a complex set of environmental sensors and has been considered the highest virulence factor of this pathogen [3]. This transition time causes mechanical disruption of the epithelial surface and augments the expression of fungal virulence factors [17]. Previous studies showed that some components of cell wall surface could be responsible of the invasion and aggressiveness of this fungus [18]. Furthermore, $C$. albicans also produces a number of secretory product connected to the development of infection [19] [20]. Actuallya variety of oral and topical preparations are available for treatment of uncomplicated yeast infections: vulvovaginal candidiasis is treated with anti-fungal drugs, administered p/os or topically, as Clotrimazole $1 / 2 \%$ cream [21], Miconazole $2 \%$ - 4\% cream, or Miconazole 100 - 200 $\mathrm{mg}$ towards vaginal tablets [22], Tioconazole $6.5 \%$ cream $5 \mathrm{~g}$ [23]. Among intravaginal drugs there are: Butoconazole $2 \%$ cream [22], Terconazole $0.4 \%$ cream, Terconazole 
$0.8 \%$ cream, Terconazole $80 \mathrm{mg}$ vaginal tablets. As an oral agent, Fluconazole $150 \mathrm{mg}$ is usually administered as a single dose [24]. Nevertheless, it is necessary to keep in mind that oral agents are often associated with a wide range of systemic effects including gastrointestinal disorders and headache [25] [26], while topical treatments often require long-term therapies and sometimes does not show the desired effect. For that reason some alternative approaches have been investigated as preventive agents in the past [6]. In this scenario, the aim of this pilot uncontrolled study was to test the efficacy of a new biguanide compound, $\mathrm{PHMB}$ vaginal solution, for the treatment of vulvovaginal candidiasis. $\mathrm{PHMB}$ is usually known as polihexanide and it is one of the modern antiseptic preparation combining a broad antimicrobial spectrum with low toxicity and high tissue compatibility [27]. It belongs to the chemical family of antiseptic biguanides. It has been used since the early nineteen-fifties as a hard surface disinfectant, water treatment agent (algaecide and sanitizer, in swimming pools, SPAs and water tanks), and preservative agent in several products due to its bacteriostatic or bactericidal properties. Previous studies showed that PHMB is effective against pathogens such as bacteria, amoebae and yeast [28] [29] [30] [31], and it has been successfully used in the treatment of bacterial vaginosis [7] [8] [9] [10] [11]. The outermost surface of bacterial cells universally carries a net negative charge, often stabilized by the presence of divalent cations such as $\mathrm{Mg}^{2+}$ and $\mathrm{Ca}^{2+}$. $\mathrm{PHMB}$ was shown to bind rapidly to the envelope of both Gram-positive and Gram-negative bacteria and in doing so displaces the otherwise stabilizing presence of $\mathrm{Ca}^{2+}$ [32]. The antimicrobial activity of PHMB is due to the exclusive interaction with acidic and negatively charged phospholipids in the bacterial membrane. One additional feature is that, this interaction tends to become concentrated around any point of maximum charge density within the membrane [33] [34]. It has been shown that integral proteins constitute such sites. The initial interactions of PHMB and the membrane is concentrated around such proteins, leading to a loss of their function by inflicting changes in their boundary phospholipid environment. This interaction leads to increased fluidity, permeability, and loss of integrity of membranes, followed by the disruption of the bacterial metabolism and the death of the organism [35] [36]. The ability of PHMB to create single lipid domains within heterogeneous lipid-bilayers is clearly a function of polymer chain length with longer polymers, being able to form the larger domains and hence the greater perturbation of membrane function. As antibacterial, $\mathrm{PHMB}$ was recognized as possessing superior antimicrobial effect to other cationic biocides and this may be related to its chemical structure, constituted by 10 - 12 monomers. Moreover, in comparison to other antiseptics, PHMB was the most suitable agent with a biocompatibility index (BI) greater than 1 combined with a low cytotoxicity [34] [37] [38]. The PHMB therefore, not only embodies the attributes of the bis-biguanides in terms of antimicrobial action, but it does not affect the saprophyte flora of vagina [10]. Herrera J. et al. have investigated on the molecular organization of candida cell wall and the obtained results, according to the good data reported by the in vitro study of Messick on PHMB and C.albicans, allow to speculate that the mechanism of action of PHMB in this fungus is similar to that one reported above [18] [39].

Data presented herein suggest that a vaginal solution containing PHMB is effective in the treatment of women affected by vaginal candidiasis. In fact, all the patients treated 
with a single dose of PHMB solution $0.10 \%$ experienced a clinical benefit: $80 \%$ of patients did not display candidiasis after treatment, and $20 \%$ of them presented another mixed infection. Moreover, all of them complained typical clinical mycotic signs like itching, burning, inflammation and presented typical symptoms (as oedema, erythema and excoriation) classified through a score scale before treatment (T0). After 21 days, it has been registered a statistically significant reduction of all signs, symptoms and no yeast infection was found in the microscopic analysis with a score's reduction of $50 \%$.

Due to the interesting results and the optimal safety profile, additional prospective clinical trials are requested to validate our results, which may confirm the efficacy of a single dose administration of PHMB vaginal solution in the treatment of vulvovaginal candidiasis.

\section{Conclusion}

The results showed herein prove the efficacy and safety of PHMB as a new therapeutic approach for vaginal candidiasis infection. However, this study has some limitations due to the number of cases and the absence of a control group. Therefore, additional prospective clinical trials in a large cohort of women are necessary to confirm our results. Furthermore, it could be interesting to evaluate the long-term effects on the recurrence of vaginal infections, after a treatment with this agent.

\section{Conflicts of Interest}

The authors declared that they have no conflicts of interest.

\section{References}

[1] Achkar, J.M. and Fries, B.C. (2010) Candida Infections of the Genitourinary Tract. Clinical Microbiology Reviews, 23, 253-273. https:/doi.org/10.1128/CMR.00076-09

[2] Zeng, J., Zong, L.L., Mao, T., Huang, Y.X. and Xu, Z.M. (2011) Distribution of Candida albican Genotype and Candida Species Is Associated with the Severity of Vulvovagianl Candidiasis. Journal of Southern Medical University, 31, 1649-1653.

[3] Biswas, S., Van Dijck, P. and Datta, A. (2007) Environmental Sensing and Signal Transduction Pathways Regulating Morphopathogenic Determinants of Candida albicans. Microbiology and Molecular Biology Reviews, 71, 348-376. https:/doi.org/10.1128/MMBR.00009-06

[4] Sobel, J.D., Brooker, D., Stein, G.E., Thomason, J.L., Wermeling, D.P., Bradley, B., et al. (1995) Single Oral Dose Fluconazole Compared with Conventional Clotrimazole Topical Therapy of Candida Vaginitis. Fluconazole Vaginitis Study Group. American Journal of Obstetrics \& Gynecology, 172, 1263-1268. https:/doi.org/10.1016/0002-9378(95)91490-0

[5] Mendling, W., Brasch, J., Cornely, O.A., Effendy, I., Friese, K., Ginter-Hanselmayer, G., Hof, H., Mayser, P., Mylonas, I., Ruhnke, M., Schaller, M. and Weissenbacher, E.R. (2015) Guideline: Vulvovaginal Candidosis (AWMF 015/072), S2k (Excluding Chronic Mucocutaneouscandidosis). Mycoses, 58, 1-15. https:/doi.org/10.1111/myc.12292

[6] Sweeten, K.M. and Eriksen, N.L. (1997) Chlorexidine versus Sterile Water Vaginal Wash during Labor to Prevent Peripartum Infection. American Journal of Obstetrics \& Gynecology, 176, 426-430. https:/doi.org/10.1016/S0002-9378(97)70510-6

[7] Minozzi, M., Gerli, S., Di Renzo, G.C., Papaleo, E. and Ferrari, A. (2008) The Efficacy and 
Safety of a Single Dose of Polyhexamethylene Biguanide Gynaecologic Solution versus a Seven-Dose Regimen of Vaginal Clindamycin Cream in Patients with Bacterial Vaginosis. European Review for Medical and Pharmacological Sciences, 12, 59-65.

[8] Gerli, S., Rossetti, D. and Di Renzo, G.C. (2003) A New Approach for the Treatment of Bacterial Vaginosis: Use of Polyhexamethylene Biguanide. A Prospective, Randomized Study. European Review for Medical and Pharmacological Sciences, 7, 127-130.

[9] Gentile, A., Gerli, S. and Di Renzo, G.C. (2012) A New Non-Invasive Approach Based on Polyhexamethylene Biguanide Increases the Regression Rate of HPV Infection. BMC Clinical Pathology, 12, 17. https:/doi.org/10.1186/1472-6890-12-17

[10] Marelli, G., Papaleo, E., Origoni, M., Caputo, L. and Ferrari, A. (2005) Polyhexamethylene Biguanide for Treatment of External Genital Warts: A Prospective, Double-Blind, Randomized Study. European Review for Medical and Pharmacological Sciences, 9, 369-372.

[11] Gerli, S., Bavetta, S. and Di Renzo, G.C. (2012) Antisepsis Regimen in the Surgical Treatment of HPV Generated Cervical Lesions: Polyhexamethylene Biguanide vs Chlorhexidine. European Review for Medical and Pharmacological Sciences, 16, 1994-1998.

[12] Anderson, D.J., Marathe, J. and Pudney, J. (2014) The Structure of the Human Vaginal Stratum Corneum and Its Role in Immune Defense. American Journal of Reproductive Immunology, 71, 618-623. https:/doi.org/10.1111/aji.12230

[13] Brocklehurst, P. and Mindel, A. (1991) Recurrent Genital Infections. British Journal of Sexual Medicine, 18, 54-57.

[14] Glover, D.D. and Larsen, B. (1998) Longitudinal Investigation of Candida Vaginitis in Pregnancy: Role of Superimposed Antibiotic Use. Obstetrics \& Gynecology, 91, 115-118. https:/doi.org/10.1016/S0029-7844(97)00588-7

[15] Monif, G.R.G. (1985) Pathogenesis and Classification of Vulvovaginal Candidiasis. American Journal of Obstetrics \& Gynecology, 152, 935-939. https:/doi.org/10.1016/S0002-9378(85)80004-1

[16] Thrumbore, D.J. and Sobel, J.D. (1986) Recurrent Vulvovaginal Candidiasis: Vaginal Epithelial Cells Susceptibility to Candida albicans Adherence. Obstetrics \& Gynecology, 67, 810-812. https:/doi.org/10.1097/00006250-198606000-00012

[17] Gil-Bona, A., Parra-Giraldo, C.M., Hernáez, M.L., Reales-Calderon, J.A., Solis, N.V., Filler, S.G., Monteoliva, L. and Gil, C. (2015) Candida albicans Cell Shaving Uncovers New Proteins Involved in Cell Wall Integrity, Yeast to Hypha Transition, Stress Response and HostPathogen Interaction. Journal of Proteomics, 127, 340-351. https:/doi.org/10.1016/j.jprot.2015.06.006

[18] Ruiz-Herrera, J., Elorza, M.V., Valentin, E. and Sentandreu, R. (2006) Molecular Organization of Cell Wall of Candida albicans and Its Relation to Pathogenicity. FEMS Yeast Research, 6, 14-29. https:/doi.org/10.1111/j.1567-1364.2005.00017.x

[19] Taylor, B.N., Staib, P., Binder, A., Biesemeier, A., Sehnal, M., et al. (2005) Profile of Candida albicans-Secreted Aspartic Proteinase Elicited during Vaginal Infection. Infection and Immunity, 73, 1828-1835. https:/doi.org/10.1128/IAI.73.3.1828-1835.2005

[20] Schaller, M., Borelli, C., Korting, H.C. and Hube, B. (2005) Hydrolytic Enzymes as Virulence Factors of Candida albicans. Mycoses, 48, 365-377. https:/doi.org/10.1111/j.1439-0507.2005.01165.x

[21] Crowley, P.D. and Gallagher, H.C. (2014) Clotrimazole as a Pharmaceutical: Past, Present and Future. Journal of Applied Microbiology, 117, 611-617.

https:/doi.org/10.1111/jam.12554

[22] Bradbeer, C.S., Mayhew, S.R. and Barlow, D. (1985) Butoconazole and Miconazole in Treating Vaginal Candidiasis. Genitourinary Medicine, 61, 270-272.

https:/doi.org/10.1136/sti.61.4.270 
[23] Stein, G.E., Gurwith, D., Mummaw, N. and Gurwith, M. (1986) Single-Dose Tioconazole Compared with 3-Day Clotrimazole Treatment in Vulvovaginal Candidiasis. Antimicrobic Agents and Chemotherapy, 29, 969-971. https:/doi.org/10.1128/AAC.29.6.969

[24] 2015 Sexually Transmitted Diseases Treatment Guidelines.

[25] Nurbhai, M., Grimshaw, J., Watson, M., Bond, C., Mollison, J. and Ludbrook, A. (2007) Oral versus Intra-Vaginal Imidazole and Triazole Anti-Fungal Treatment of Uncomplicated Vulvovaginal Candidiasis (Thrush). Cochrane Database System Review, 17, CD002845. https:/doi.org/10.1002/14651858.cd002845.pub2

[26] Das Neves, J., Pinto, E., Teixeira, B., Dias, G., Rocha, P., Cunha, T., Santos, B., Amaral, M.H. and Bahia, M.F. (2008) Local Treatment of Vulvovaginal Candidosis: General and Practical Considerations. Drugs, 68, 1787-1802. https:/doi.org/10.2165/00003495-200868130-00002

[27] Hübner, N.O. and Kramer, A. (2010) Review on the Efficacy, Safety and Clinical Applications of Polihexanide, a Modern Wound Antiseptic. Skin Pharmacology and Physiology, 23, 17-27. https:/doi.org/10.1159/000318264

[28] McCauley, R.L., Linares, H.A., Pelligrini, V., Herndon, D.N., Robson, M.C. and Heggers, J.P. (1989) In Vitro Toxicity of Topical Antimicrobial Agents to Human Fibroblasts. Journal of Surgical Research, 46, 267-274. https:/doi.org/10.1016/0022-4804(89)90069-3

[29] Moore, K. and Gray, D. (2007) Using PHMB Antimicrobial to Prevent Wound Infection. Wounds UK, 3, 96-102.

[30] Müller, G., Koburger, T. and Kramer, A. (2013) Interaction of Poly(Hexamethylene Biguanide) Hydrochloride (PHMB) with Phosphatidylcholine Containing O/W Emulsion and Consequences for Microbicidal Efficacy and Cytotoxicity. Chemico-Biological Interactions, 201, 58-64. https:/doi.org/10.1016/j.cbi.2013.01.001

[31] Choy, C.K., Cho, P. and Boost, M.V. (2013) Cytotoxicity of Rigid Gas-Permeable Lens Care Solutions. Clinical and Experimental Optometry, 96, 467-471. https:/doi.org/10.1111/cxo.12039

[32] Broxton, P., Woodcock, P.M. and Gilbert, P. (1984) Binding of Polyhexamethylene Biguanides to the Cell Envelope of Escherichia coli. Microbios, 41, 15-22.

[33] Ikeda, T., Tazuke, S. and Bamford, C.H. (1985) Interaction of Membrane Active Biguanides with Negatively Charged Species. A Model for Their Interaction with Target Sites in Microbial Membranes. Journal of Chemical Research, 6, 180-181.

[34] Ikeda, T., Tazuke, S., Ledwith, A. and Bamford, C.H. (1985) Spectroscopic Studies on the Interaction of Polymeric In-Chain Biguanide Biocides with Phospholipid Membranes. Bulletin of the Chemical Society of Japan, 58, 705-709. https:/doi.org/10.1246/bcsj.58.705

[35] Gilbert, P. and Moore, L.E. (2005) Cationic Antiseptics: Diversity of Action under a Common Epithet. Journal of Applied Microbiology, 99, 703-715. https:/doi.org/10.1111/j.1365-2672.2005.02664.x

[36] Yasuda, K., Ohmizo, C. and Katsu, T. (2003) Potassium and Tetraphenylphosphonium IonSelective Electrodes for Monitoring Changes in the Permeability of Bacterial Outer and Cytoplasmic Membranes. Journal of Microbiological Methods, 54, 111-115. https:/doi.org/10.1016/S0167-7012(02)00255-5

[37] Ikeda, T., Tazuke, S. and Watanabe, M. (1983) Interaction of Biologically Active Molecules with Phos-Pholipid Membranes. Fluorescence Depolarization Studies on the Effect of Polymeric Biocide Bearing Biguanide Groups in the Main Chain. Biochimicaet Biophysica Acta, 735, 380-386. https:/doi.org/10.1016/0005-2736(83)90152-9

[38] Müller, G. and Kramer, A. (2008) Biocompatibility Index of Antiseptic Agents by Parallel Assessment of Antimicrobial Activity and Cellular Cytotoxicity. Journal of Antimicrobial Chemotherapy, 61, 1281-1287. https:/doi.org/10.1093/jac/dkn125 
[39] Messick, C.R., Pendland, S.L., Moshirfar, M., Fiscella, R.G., Losnedahal, K.J., Schriever, C.A. and Schreckenberger, P.C. (1999) In-Vitro Activity of Polyhexamethylene Biguanide (PHMB) against Fungal Isolates Associated with Infected Keratitis. Journal of Antimicrobial Chemotherapy, 44, 297-298. https:/doi.org/10.1093/jac/44.2.297

Submit or recommend next manuscript to SCIRP and we will provide best service for you:

Accepting pre-submission inquiries through Email, Facebook, LinkedIn, Twitter, etc. A wide selection of journals (inclusive of 9 subjects, more than 200 journals)

Providing 24-hour high-quality service

User-friendly online submission system

Fair and swift peer-review system

Efficient typesetting and proofreading procedure

Display of the result of downloads and visits, as well as the number of cited articles

Maximum dissemination of your research work

Submit your manuscript at: http://papersubmission.scirp.org/

Or contact ojog@scirp.org 